\title{
Mental Health Status and Related Factors Among Visually Impaired Athletes
}

\author{
Yasuko Kohda ${ }^{\mathrm{a}, \mathrm{b}}$, Takafumi Monma ${ }^{\mathrm{c}}$, Maki Yamane ${ }^{\mathrm{a}, \mathrm{d}}$, Toshihito Mitsuid, \\ Kayoko Ando ${ }^{\text {d }}$, Subrina Jesmin ${ }^{\mathrm{c}}$, Fumi Takeda ${ }^{\mathrm{c}, ~ e}$
}

\begin{abstract}
Background: A growing body of pieces of evidence suggests that sport activity is of potential importance both for physical and mental health. To date, there is a lack of information and evidence regarding the mental health of visually impaired people playing some extent of sports and recognized as athletes with renowned career track. The present study aims to clarify the mental health status and its related factors in visually impaired athletes.
\end{abstract}

Methods: The current study was a questionnaire-based cross-sectional investigation. Visually impaired athletes $(\mathrm{n}=81$; men: $72.8 \%$; average age: $32.8 \pm 12.0$ years) engaged in Paralympic sports events namely track and field (marathon), goalball, swimming, blind soccer, and judo were the study subjects from leading institutions in Japan. A diverse range of issues were included in a questionnaire survey like attributes, condition of visual impairment, competition activities, competition stressors, social support, and mental health status (recorded through the K6 scale). Logistic regression analyses were performed with mental health status as a dependent variable and other studied parameters as independent variables.

Results: A total of $21.0 \%$ of study participants (11.9\% of men and $45.5 \%$ of women) showed bad mental health condition. Results of multivariate logistic regression analysis showed that "female" (odds ratio (OR) 11.94, 95\% confidence interval (CI) $2.60-54.76, \mathrm{P}=$ 0.001 ), "higher evaluation from one's surroundings for competition stressors" (OR 5.74, 95\% CI 1.34 - 24.60, P = 0.019), and "lower social support from family members" (OR 3.97, 95\% CI 1.03 - 15.25, $\mathrm{P}=0.045)$ were the risk factors of bad mental health.

Manuscript submitted September 12, 2019, accepted October 4, 2019

aGraduate School of Comprehensive Human Sciences, University of Tsukuba, 1-1-1 Tennodai, Tsukuba-shi, Ibaraki 305-8577, Japan

${ }^{b}$ Research and Support Center on Higher Education for People with Disabilities, Tsukuba University of Technology, 4-12-7 Kasuga, Tsukuba-shi, Ibaraki 305-8521, Japan

'Faculty of Health and Sport Sciences, University of Tsukuba, 1-1-1 Tennodai, Tsukuba-shi, Ibaraki 305-8577, Japan

dFaculty of Sport Sciences, Nihon Fukushi University, Okuda, Mihama-cho, Chita-gun, Aichi 470-3295, Japan

${ }^{e}$ Corresponding Author: Fumi Takeda, Faculty of Health and Sport Sciences, University of Tsukuba, 1-1-1 Tennodai, Tsukuba-shi, Ibaraki 305-8574, Japan. Email: takeda.fumi.fe@u.tsukuba.ac.jp

doi: https://doi.org/10.14740/jocmr3984
Conclusions: The mental health status among visually impaired athletes might be almost the same level as non-visually impaired athletes and general population, and have relation to gender, stress of evaluation from surroundings during competition, and social support from family members. It may be necessary to pay attention especially to women, and improve one's surroundings of competition stressors and family social support to maintaining the mental health of visually impaired athletes.

Keywords: Mental health; Visual impairment; Athletes; Logistic regression analysis

\section{Introduction}

Visual impairment is a state characterized by a decreased ability to see to the degree that causes problems and is not fixable by usual means, such as glasses, contact lenses [1]. The global prevalence estimates in 2010 explored that 285 million $(4.2 \%)$ had visual impairments, 39 million were blind, and 246 million had low vision [2]. Indeed, blindness and visual impairment can severely affect the quality of life with tremendous negative impact. Blind people have difficulty and discomfort in their daily life activities (e.g. driving, reading, sewing, and walking) [1].

Several shreds of evidence indicate that the mental health status of visually impaired people is not sound and good [3]. About one-third of people with visual impairment experience subthreshold depression and anxiety (indicating subclinical symptoms) [4-6], while around 5\% to $7 \%$ have a major depressive disorder [4-6] and 7\% have an anxiety disorder with a higher percentage than those having a healthy vision [4]. Impaired vision is associated with mental fatigue [7, 8], less social contact $[9,10]$ and can induce feelings of loneliness and social isolation $[9,10]$ and these psychological disorders are even evident in children [11-16]. This global trend of mental health disturbance among visually impaired people is also prevalent and familiar in Japan [17]. Mental health status measured by General Health Questionnaire-28 (GHQ28) was worse in visually impaired people than in sighted people [17].

Indeed, sport and physical activities (PAs) are one of the practical approaches for the stability of individual mental health status with further betterment [18].

Visually impaired individuals, including children, tend to have lower PA levels than their peers without disabilities. While 
$56 \%$ of Japanese adults without any disability perform sports/ PA once or more per week [19], only $20 \%$ of Japanese visually impaired adults (over 18 years old) [20], or only $30 \%$ over age 12 years with visually impairment [21] do sport activity to a similar extent. Visually impaired people would be limited to have the chance of sport activity, and social barriers pose potential impact on main problems preventing blind or partially sighted subjects from practicing sporting activity [22], although the limitations due to concerns of other people for the safety of blind subjects [23] and self-imposed barriers due to the fear of being ridiculed [24] should also be considered.

To date, little research has been conducted on the relationship between mental health and sport activity of visually impaired people across the globe. Among those reporting no impairment, doing $<1$ day per week of PA was associated with having lower levels of well-being both physically and mentally at follow-up in comparison to those who were performing $\geq 1$ day of PA. For those who have evident visual impairment, the mental health benefits of attending weekly PA compared with conducting non-weekly PA were observed only among those who were more emotionally unstable or introvert at baseline [25]. Further longitudinal studies are warranted to examine in depth whether the mental health responses of PA may be dependent on the adolescent's vision status with a crucial impact [25].

The mental health status of the students with visual impairments differs according to their degree of disability; the blind students had poorer mental health than those with low vision [26]. Visually impaired students who participated in extracurricular sports activities in junior high and high schools had more stable and better mental health than those who did not, and visually impaired students' experiences of extracurricular sports activities appeared to have positive effects on their mental health [26].

There are few reports on the mental health of visually impaired people; further to date, there is no report on the mental health of visually impaired athletes, including high-level athletes. Based on the above facts, it might be essential to explore the nature and characteristics of mental health in disabled population like the visually impaired who have an established career track of sports activities; whether physical disability like visual impairment would pose a potential impact even on the mental health status of these types of elite athletes. Thus the present study aimed to clarify with in-depth and comprehensive profiling the mental health status and the related factors among visually impaired athletes.

\section{Materials and Methods}

\section{Study population and procedure}

This population-based cross-sectional study was conducted from October 2017 to October 2018 among 99 visually impaired athletes volunteered engaged in Paralympic sports events in Japan, using convenience sampling technique. The researchers contacted the primary head of each leading respective sports organization of Paralympic events namely track and field (marathon), goalball, swimming, blind soccer, and judo, and arranged responsible personnel for each organization to select the participants for the survey.

Since the respondents were visually impaired, the questionnaire was prepared in multiple forms: three different character sizes (regularized characters and two kinds of enlarged characters), a Braille version, a Digital Accessible Information System (DAISY) version, and an online version. Each study participant was requested to answer the questions after choosing the most convenient format from these options. The participants had no other known disorder/disability except being visually impaired. Eighty-one participants who filled up the questionnaire entirely among 99 volunteers participated in the study were included in the analysis (the valid response ratio was $81.8 \%$ ).

\section{Measurements}

\section{Mental health status}

Mental health status was examined and determined using the Japanese version of the K6 scale [27], a powerful measurement tool to discriminate between community cases and non-cases of Diagnostic and Statistical Manual of Mental Disorders-IV (DSM-IV) [28]. Respondents made their answers regarding six items on a 5-point Likert scale, and the responses on each item were then transformed to the scores ranging from 0 to 4 points. A higher total score indicates a poorer mental health status. All respondents were categorized into two groups: "good mental health status" (scores less than or equal to 4 points) or "bad mental health status" (ratings with 5 points or above); the 5-point mark has been identified as the optimal cut-off point to screen the mood and anxiety disorders/status in Japan (100\% sensitivity and $68.7 \%$ specificity), and also has been used in previous Japanese studies [29, 30]. The Japanese version of the K6 scale has been validated [27] and well-characterized, and the internal consistency reliability (Cronbach's alpha) of the scale observed in the current study was 0.86 .

\section{Attributes}

Attributes included age, gender, and residential style (living with family/living alone or without family).

\section{Condition of visual impairment}

Total study participants were divided into three categories according to criteria adopted by "IBSA Classification Rules December 2018" [31]. B1: Visual acuity is less than LogMAR 2.60; B2: Visual acuity ranges from LogMAR 1.50 to 2.60 (inclusive), and/or the visual field is constricted to a diameter of fewer than 10 degrees; and B3: Visual acuity ranges from LogMAR 1 to 1.40 (inclusive), and/or the visual field is constricted to a diameter of fewer than 40 degrees. Condition of visual impairment included also causing time of disability (congenital/acquired). 


\section{Competition activities}

Competition activities included namely the sports events, athletic career (years), performance level (top 3 of international games/international/prizes at national games/others), athletic level (Japanese delegate/others), training days per week (times), and total training time per week (minutes).

\section{Competition stressors}

To assess competition stressors, we used the Competition Stressor Scale developed by Asanuma et al [32]. This scale comprises 28 question items that record frequency over the past month. Each item is rated on a 4-point scale from 0 ("not at all") to 3 ("very often"). This scale comprises five factors, and the scale range for each is as follows: "interpersonal relationships", 0 - 24 points; "competition results", 0 - 9 points; "evaluations from one's surroundings", 0 - 15 points; "expectations and pressure from others", 0 - 15 points; and "motivation loss", 0 - 21 points. Higher scores indicate higher stress level. This scale's relevance has been shown by previous studies [32], and Cronbach's alpha coefficients for respondents were as follows in the current study: interpersonal relationships, 0.75; competition results, 0.84; evaluations from one's surroundings, 0.79; expectations and pressure from others, 0.79 ; and motivation loss, 0.72 .

\section{Social support}

To assess social support in the current study, the modified Brief Scale of Social Support by Miura et al [33] was used. This scale consists of five items related to emotional, instrumental, and practical support. Family members, friends of athletic peers, friends of non-athletic peers, and coaches were specified as four sources of support, and the same questions were asked about each of these sources. A score ranging from 1 to 4 was given to each answer, resulting in a total score between 5 and 20 for each supported source. Higher scores indicate greater awareness of support. The Cronbach's alpha coefficients for this study's respondents were as follows: family members, 0.90 ; friends of athletic peers, 0.82 ; friends of non-athletic peers, 0.84; and coaches, 0.89 .

\section{Ethics approval}

The survey was approved in advance by the Research Ethics Committee of the Faculty of Health and Sport Sciences of the University of Tsukuba, Japan (Reference No: Tai 29-44).

\section{Statistical analysis}

Differences between the two groups by mental health status were calculated using Fisher's exact test and unpaired $t$-test, a non-parametric test for independent samples (Mann-Whitney
U-test). Univariate and multivariate logistic regression analysis was done with mental health as a dependent variable and other studied parameters as independent variables. Age, athletic career, training day per week, total training time per week, five competition stressors, and four social supports were divided into two groups by 50 percentile. In the multivariate logistic regression analysis with forward stepwise method (likelihood ratio), the factors which had a significant relation with mental health in univariate logistic regression analysis were only used as independent variables. It was confirmed that no issue of multicollinearity existed among the independent variables. The level of significance for all analyses was set at $\mathrm{P}<$ 0.05 . All statistical analyses and interpretation were made using IBM SPSS version 23.0 (IBM Corp., Armonk, NY, USA).

\section{Results}

Table 1 shows the participants' attributes, condition of visual impairment, and competition activities. Mean age in the study population was $32.8 \pm 12.0$ years (aged 15 - 63 years), including $72.8 \%$ (59) male subjects. A total of $54.3 \%$ of study participants live with their families; the rest of the participants live alone or without families (45.7\%). Based on visual impairment assessment, $38.3 \%$ were at B1 (blind) stage, $30.9 \%$ at B2 (severe low vision) stage, and the rest of the participants $(30.9 \%)$ at B3 (low vision) stage. It seemed that $59.3 \%$ of study participants were congenitally visually impaired.

Distribution of competitive activities is as follows: sports events of them were 18 track and field (marathon) athletes (22.2\% of total study participants); 11 goalball players $(13.6 \%)$; 23 swimmers $(28.4 \%)$; 14 blind soccer players $(17.3 \%)$; and 15 judo players $(18.5 \%)$. The participants had athletic career of 11.5 years on average with both international and domestic high reputations through winning of medals and prizes, and spent more than 5 days and 778 min for training per week.

Table 2 shows the participants' status of mental health, social support, and competition stressors. Sixty-four study subjects had good K6 score less than or equal to 4 points $(79.0 \%$ of total study subjects); in contrast, 17 participants had bad K6 score more than 5 in absolute value (the rest $21.0 \%$ of total study subjects). Among competition stressors surveyed in the current study, competition results score was at the side of relatively high (mean score 4.7 out of 9) level, while evaluations from one's surroundings score occupied a relatively low (mean score 2.7 out of 9) level. Social support scores in terms of all aspects investigated, namely, family members, friends of athletic peers, friends of non-athletic peers, and coaches were on average around 15 .

Table 3 shows the characteristics difference between participants with good and bad mental health. There were significant differences between two groups stratified by mental health status (good or bad) in gender, competition stressors of evaluations from one's surroundings, and those of motivation loss, and social support from family members. The rate of bad mental health differed by gender (men: $11.9 \%$, women: $45.5 \%$ ), the level of evaluation from one's surroundings stressor and motivation loss stressor, and social support from family members. 
Table 1. Participants' Attributes, Condition of Visual Impairment and Competition Activities $(n=81)$

\begin{tabular}{|c|c|}
\hline & Mean \pm SD or $n(\%)$ \\
\hline \multicolumn{2}{|l|}{ Attributes } \\
\hline Age (years) & $32.8 \pm 12.0$ \\
\hline \multicolumn{2}{|l|}{ Gender } \\
\hline Male & $59(72.8 \%)$ \\
\hline Female & $22(27.2 \%)$ \\
\hline \multicolumn{2}{|l|}{ Residential style } \\
\hline Living with family & $44(54.3 \%)$ \\
\hline Living alone or without family & $37(45.7 \%)$ \\
\hline \multicolumn{2}{|l|}{ Condition of visual impairment } \\
\hline \multicolumn{2}{|l|}{ Athletic classification ${ }^{\mathrm{a}}$} \\
\hline B1 & $31(38.3 \%)$ \\
\hline $\mathrm{B} 2$ & $25(30.9 \%)$ \\
\hline B3 & $25(30.9 \%)$ \\
\hline \multicolumn{2}{|l|}{ Causing time of disability } \\
\hline Congenital & $48(59.3 \%)$ \\
\hline Acquired & $33(40.7 \%)$ \\
\hline \multicolumn{2}{|l|}{ Competition activities } \\
\hline \multicolumn{2}{|l|}{ Sports events } \\
\hline Track and field (marathon) & $18(22.2 \%)$ \\
\hline Goalball & $11(13.6 \%)$ \\
\hline Swimming & $23(28.4 \%)$ \\
\hline Blind soccer & $14(17.3 \%)$ \\
\hline Judo & $15(18.5 \%)$ \\
\hline Athletic career (years) & $11.5 \pm 9.0$ \\
\hline \multicolumn{2}{|l|}{ Performance level } \\
\hline International medalist & $26(32.1 \%)$ \\
\hline International & $16(19.8 \%)$ \\
\hline Prizes at national competitions & $23(28.4 \%)$ \\
\hline Others & $16(19.8 \%)$ \\
\hline \multicolumn{2}{|l|}{ Athletic level } \\
\hline Japanese delegate & $47(58.0 \%)$ \\
\hline Others & $34(42.0 \%)$ \\
\hline Training day per week (times) & $5.3 \pm 1.8$ \\
\hline Total training time per week (minutes) & $778.3 \pm 429.9$ \\
\hline
\end{tabular}

SD: standard deviation. ${ }^{\mathrm{a}} \mathrm{B} 1$ : blind; B2: severe low vision; B3: low vision.

Table 4 shows the results of logistic regression analysis. In univariate analysis, gender (odds ratio (OR) 6.19, 95\% confidence interval (CI) $1.96-19.99, \mathrm{P}=0.002)$, athletic classification B3 (OR 3.80, 95\% CI $1.00-14.36, \mathrm{P}=0.049$ ), competition result stressor (OR 4.28, 95\% CI $1.34-13.67, \mathrm{P}=$ 0.014 ), evaluations from one's surroundings stressor (OR 3.50, $95 \%$ CI $1.14-10.73, \mathrm{P}=0.028)$, motivation loss stressor (OR
$3.75,95 \%$ CI $1.22-11.54, \mathrm{P}=0.021)$, and social support from family members (OR 3.65, 95\% CI 1.20 - 11.07, P = 0.022) had related to mental health. In multivariate logistic regression analysis, gender (OR 11.94, 95\% CI 2.60 - 54.76, P = 0.001), evaluation from one's surroundings (OR 5.74, 95\% CI 1.34 - 24.60, $\mathrm{P}=0.019)$, and social support from family members (OR 3.97, 95\% CI $1.03-15.25, \mathrm{P}=0.045$ ) had independently related to mental health. In other words, mental health status was worse in visually impaired athletes who were female and had higher evaluation from one's surroundings of competition stressors, and had lower social support from family members.

\section{Discussion}

In our best knowledge, this is the first study that clarified the mental health status of visually impaired athletes and its related factors such as attributes, condition of visual impairment, competition activities, competition stressors, and social support. This cross-sectional study was conducted using questionnaires for 81 Japanese visually impaired athletes who play Paralympic sports events, namely track and field (marathon), goalball, swimming, blind soccer, and judo.

\section{Mental health status}

The current result explored that $21.0 \%$ of visually impaired established Japanese athletes have bad mental health with a profile of psychological distress as evaluated through K6 score [27]. In a previous study, the rate of bad mental health in Japanese sighted student athletes was $28.3 \%$ of the total study subjects (using K6 score, the same item for this study) [34]. Furthermore, according to data of the comprehensive survey of living conditions (CSLC) in 2016 conducted by the Ministry of Health, Labor and Welfare (MHLW) in Japan, 30.5\% of Japanese people aged 15 - 64 years had the bad mental health (using K6 score) [35]. We drew comparison of the percentage of bad mental health between this study participants and previous surveys participants $[34,35]$ by test for equality of proportion, and there were no significant differences in the percentage between this study and both of previous surveys [34, 35]. Thus, the mental health status among visually impaired athletes seems to be similar to visually normal athletes and general population.

Contradictory to our findings, the majority of the studies suggested that older people, children, and young adults who have visual impairments developed more emotional problems than did their sighted peers [3-17]. Young people who are visually impaired may have fewer opportunities and chances to make friends and may face issues of social isolation, discrimination, and, consequently, they may develop emotional and communication problems in daily life [36], but when they are athletes, they may have more social exposure and interaction affecting their mental health positively. Accordingly, it seems that in visually impaired people who are engaged in competitive sports, their mental health was sound in the current investigation. The benefits of sports in building fitness, teaching 
Table 2. Participants' Status of Mental Health, Social Support, and Competition Stressors $(n=81)$

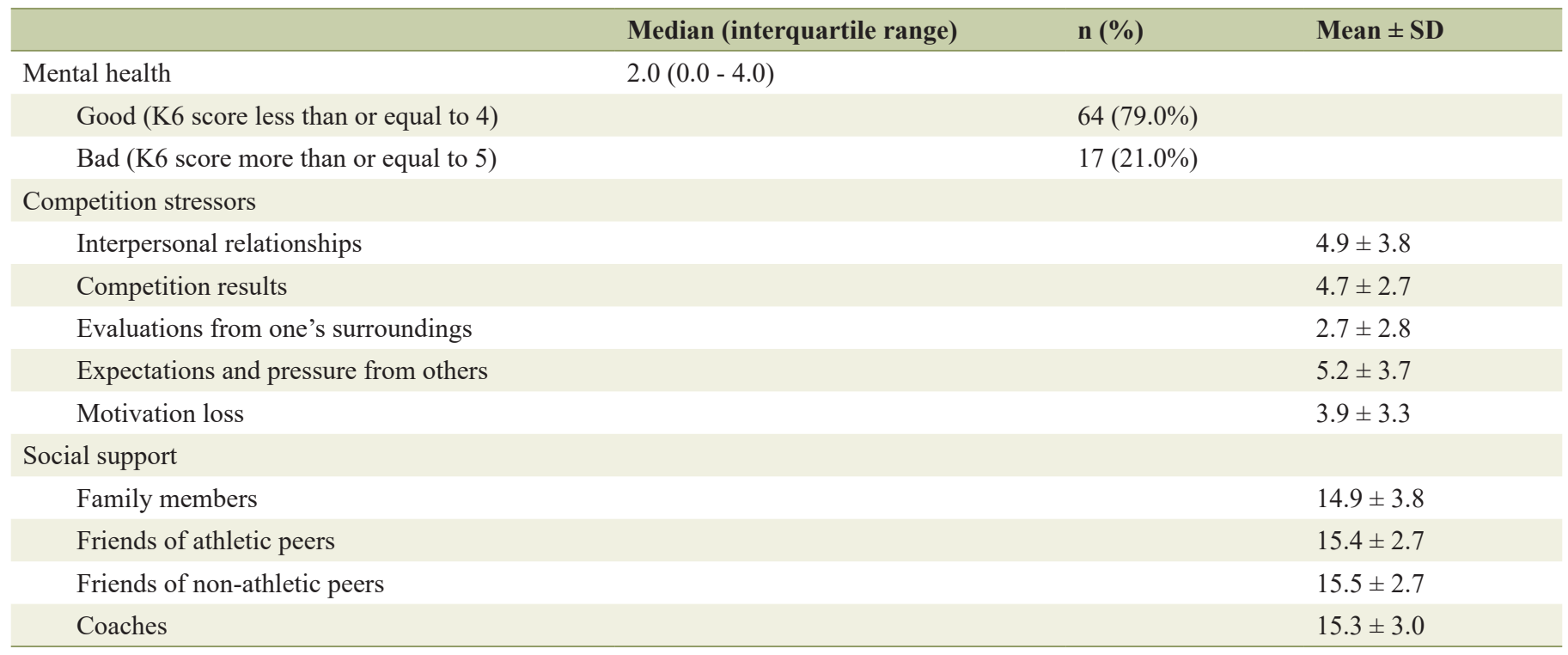

SD: standard deviation.

healthy habits and healthy competition, developing self-confidence, building social skills and friendships, and providing pleasure in the visually impaired are highly acknowledged and appreciated.

\section{Mental health related factors}

Next, we clarified the relationship between mental health and attributes, condition of visual impairment, competition activities, competition stressors, and social support in visually impaired athletes. The multivariable logistic regression analysis showed that gender, evaluation from one's surroundings of competition stressors, and social support from family members were significant variables independently related to mental health status. We found no evidence for the relationship between mental health and attributes except gender, condition of visual impairment, and competition activities. Thus, the differences in context of gender, additional evaluation from one's surroundings during competition and social support from family members seem to play a significant role in determining mental health status in the current subject.

First, mental health status in female visually impaired athletes was worse than that of men in the current study. Consistent with our findings, several past reports showed the gender difference of the mental health status in visually impaired students; girls had more serious depressive and anxiety symptoms than boys [36-39]. Our findings also agree with the majority of the literature on non-visually impaired athletes, which has found that female athletes show higher scores of anxiety and depression than male athletes [40-42]. Similarly, in general population aged 15 - 64 years, CSLC by MHLW in Japan showed that the rate of bad mental health was higher in women than in men [35]. Although we cannot exclude the biological characteristics of the female population, a study conducted in
Japan demonstrated that female athletes were more cooperative but had low levels of confidence, determination, and selfcontrol compared to the male counterpart, and demand more psychological counseling [43]. Therefore, programs aimed at improving specifically for the visually impaired female athletes should be designed with proper care and cautions to equalize social inclusion, barriers, and gender-based equity.

Second, mental health status was poor if the stressor of evaluation from one's surroundings was high (OR 5.74) implying the condition that competitive efforts and achievements of games and exercises were not acknowledged by coaches, athletic peers, or there was no time to go into the game at all, or it decreased considerably. It is highly suggested from the current findings that the coaches or peers or surrounding people should be more careful to recognize athletes and support them during competition with a positive and motivational attitude. Previous researches on non-disabled Japanese athletes reported that mental health had a relation with the stressor of interpersonal relationships [32], competition results [44], and expectation and pressure from others [45]. Thus it can be assumed that mental health-related competitive stressor differs by conditions like disability, including visual impairment in athletes.

Third, social support from family members has shown significant relation with mental health in the current study (OR 3.97), implying that good social support from family members has a potential to improve mental health in visually impaired athletes by four folds. Social support from friends or coaches had no significant relation with mental health in Japanese visually impaired athletes, as observed in the current study. This finding is not consistent with previous studies showing better social support, especially support from friends, is vital to help children with visual impairments in reducing the number and severity of their emotional problems [37, 46, 47], as well as their depression and anxiety symptoms [38, 48]. Of note, young people with visual impairments have fewer chances to 
Table 3. Comparison of Characteristics Between Participants With Good and Bad Mental Health

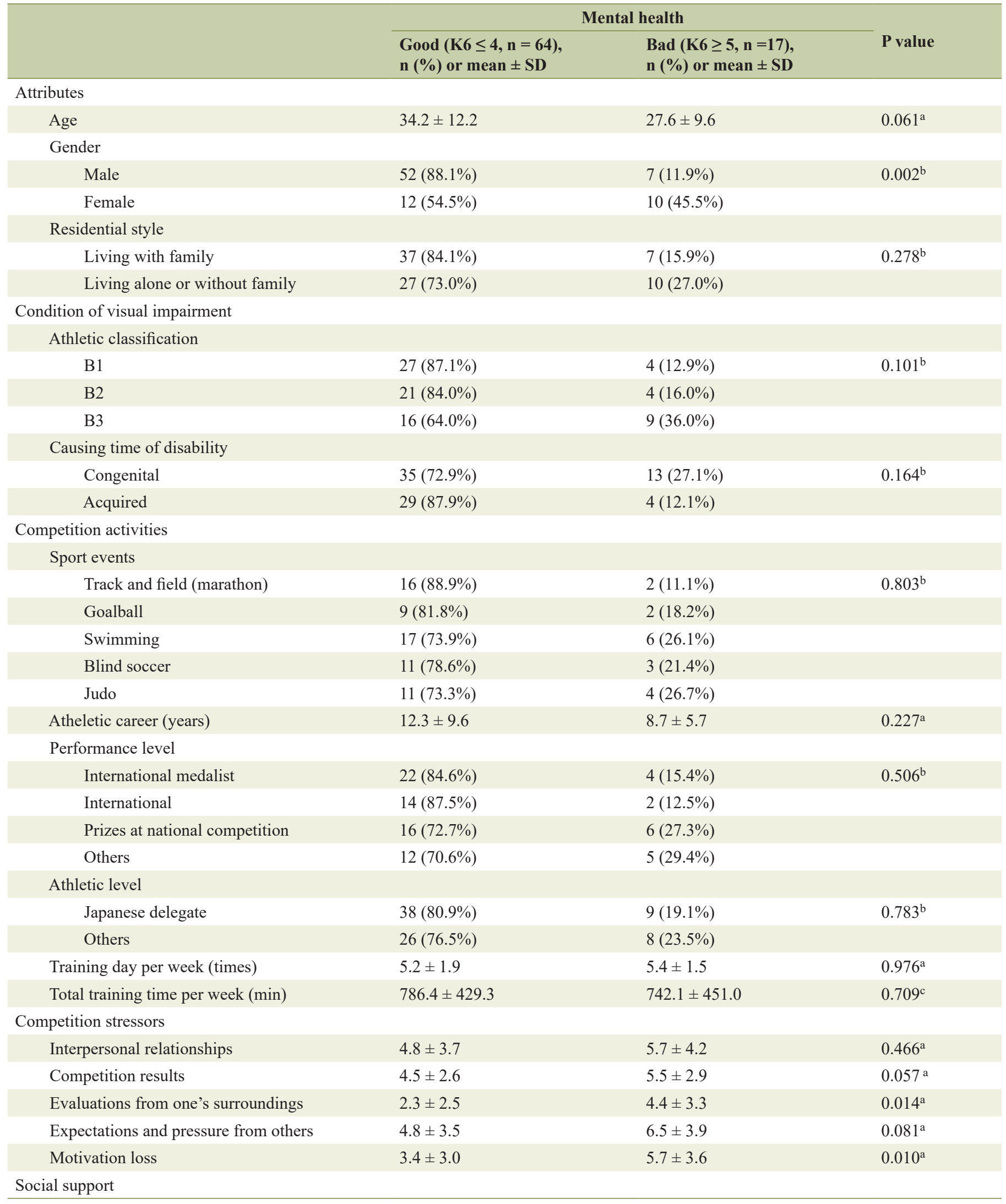


Table 3. Comparison of Characteristics Between Participants With Good and Bad Mental Health - (continued)

\begin{tabular}{|c|c|c|c|}
\hline & \multicolumn{2}{|c|}{ Mental health } & \multirow[b]{2}{*}{ P value } \\
\hline & $\begin{array}{l}\text { Good }(\mathrm{K} 6 \leq 4, \mathrm{n}=64) \\
\mathrm{n}(\%) \text { or mean } \pm \mathrm{SD}\end{array}$ & $\begin{array}{l}\text { Bad }(K 6 \geq 5, n=17) \\
n(\%) \text { or mean } \pm S D\end{array}$ & \\
\hline Family members & $15.5 \pm 3.4$ & $12.8 \pm 4.6$ & $0.028^{\mathrm{a}}$ \\
\hline Friends of athletic peers & $15.2 \pm 2.6$ & $15.9 \pm 2.8$ & $0.298^{\mathrm{a}}$ \\
\hline Friends of non-athletic peers & $15.3 \pm 2.4$ & $16.1 \pm 3.8$ & $0.116^{\mathrm{a}}$ \\
\hline Coaches & $15.2 \pm 3.2$ & $15.7 \pm 2.1$ & $0.556^{\mathrm{a}}$ \\
\hline
\end{tabular}

SD: standard deviation. Statistical methodologies are as follows: aMann-Whitney U-test, bFisher's exact test, and 'unpaired $t$-test.

make friends, face problems of social isolation and, consequently, they develop emotional and communication problems [36]. Different types of mental health problems may depend on lifestyle, support from family and friends, level of integrations, and social networks [49]. In the case of athletes with visual impairment, they already have exposure on the relationship and communication or support for each other with similarly disabled friends and/or close intimate intact sighted friends during their daily competitive activities, training and practices; visually impaired athletes thus can have opportunity to come across with both disabled and non-disabled athletes, coaches and friends not only at playground, but also at each step of daily and social life. This mixed type of practice or learning environment is unusual for completely normal eye-sighted athletes. These factors or attributes may preclude the possibility of social support from friends to be a significant variable to mental health in the current study setting.

There are several limitations to this study. First, the present study did not include control groups like non-visually impaired athletes, which poses limitation to clarifying the difference of the mental health status between visually impaired and non-impaired athletes. Second, it is a small-scale study only in Japan, with a small sample size obtained from different organizations with a convenience sampling type, not a random sampling, and therefore sampling bias cannot be excluded from current findings. Although a little missing information for a particular subject infestation was not included in the present analysis, the inclusion and exclusion criteria for sampling could be more specific and distinct. Third, because of the gender-based differential findings presented in the current study primarily based on the disproportional study participant number, future investigation with an equal number of male and female study subjects is needed. Finally, because of the nature of self-reported questionnaires, some reporting bias also cannot be ignored. It is a cross-sectional study, thus concluding causal relations between mental health and competition activities, competition stress, social support is not possible. For in-depth analysis, the prospective longitudinal study design is crucial to clarify the causal relation between mental health and the associated factors.

Despite the above mentioned major limitations, this is the first study to examine and profile the mental health status and its related factors among visually impaired athletes. These findings suggested that the mental health condition of visually impaired athletes showed almost a similar level as that in sighted athletes observed in the previous study [34]. Although as stated in Introduction section [3-17], visually impaired or physically disabled people are easily prone to develop mental or psychological distress/disturbances/disorders, whereas current study findings in visually impaired athletes exhibit a relatively low percentage of bad mental health through a globally recognized assessment tool. These results may add impact on the significance of PAs for maintaining good mental health irrespective of physical disability like visual impairment. Also, it may be necessary to pay attention especially to women's mental health and improve one's surroundings of competition stressors and family social support to maintaining the mental health of visually impaired athletes' crucial factors related to mental health in the current study context. Thus, collectively, the present study outcomes would at least contribute to the understanding and protection of mental health status and stability in the perspectives and viewpoints of physical disability in established athletes.

\section{Practical implication and future perspective}

The present findings bear tremendous impact before the Olympic and Paralympic Games scheduled to be held in Japan 2020 in an expansion of scientific evidence in the field of sport and technology especially in linkage with Paralympic events and participating athletes. Although the present study is only confined to the elite class athletes with visual impairment, future studies should focus on the mental health status of visually impaired subjects with a wide range of PAs/sports activities in a regular basis as a part of daily life habit. These current findings would be a baseline foundation platform for the subsequent deposition of further evidence in the field of mental health with a disability and conjoined PA.

\section{Conclusions}

From the current findings, we conclude that: 1) A total of $21.0 \%$ of study participants showed bad mental health condition, implying almost the similar mental health status as in non-visually impaired athletes and general population; and 2) Women, higher evaluation from one's surroundings of competition stressors, and lower social support from family members were independently related to poor mental health among visually impaired athletes. 
Table 4. Logistic Regression Analyses Investigating the Relationships Between Attributes, Condition of Visual Impairment, Competition Activities, Competition Stressors, Social Support and Mental Health

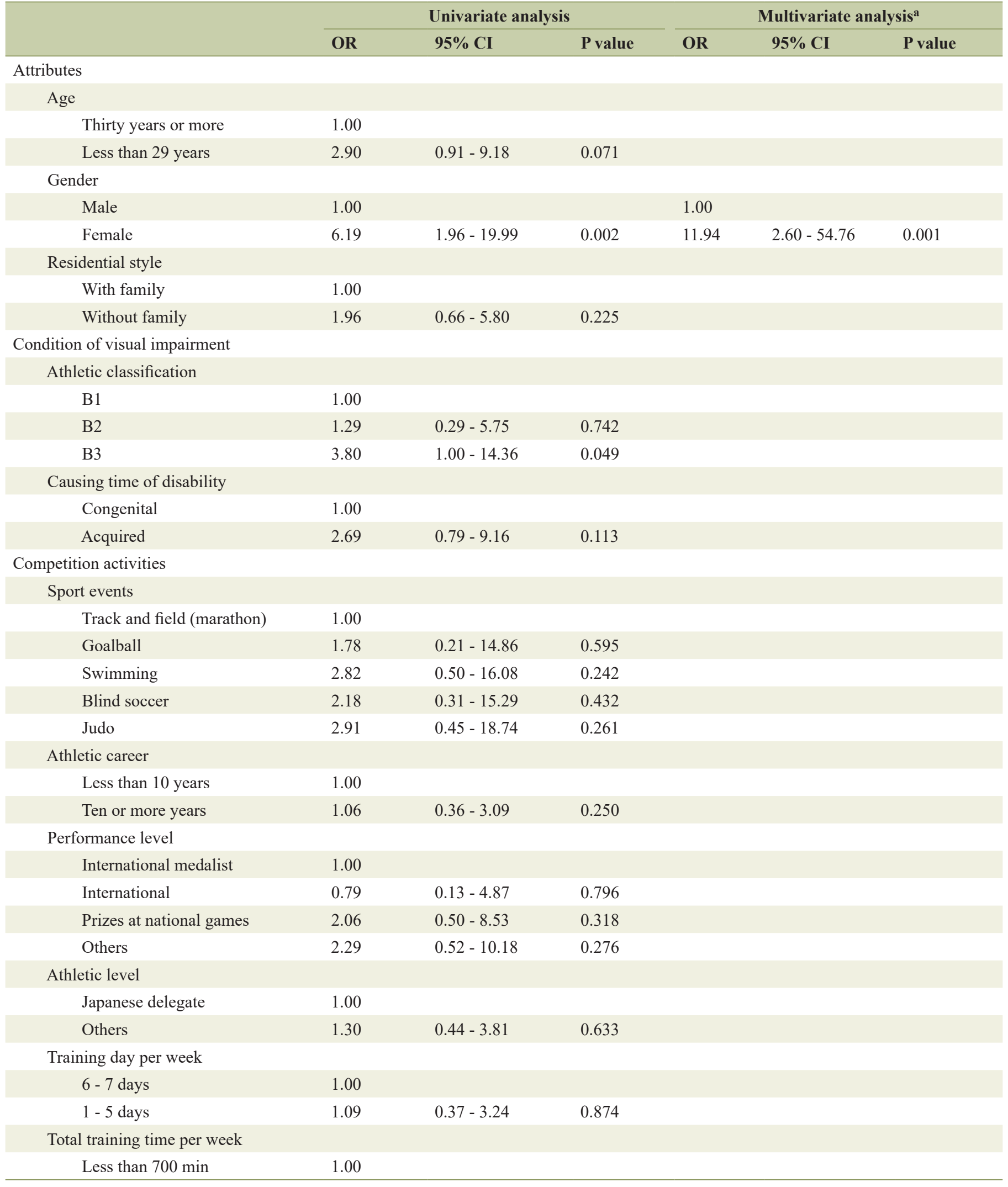


Table 4. Logistic Regression Analyses Investigating the Relationships Between Attributes, Condition of Visual Impairment, Competition Activities, Competition Stressors, Social Support and Mental Health - (continued)

\begin{tabular}{|c|c|c|c|c|c|c|}
\hline & \multicolumn{3}{|c|}{ Univariate analysis } & \multicolumn{3}{|c|}{ Multivariate analysis $^{\mathrm{a}}$} \\
\hline & OR & $95 \% \mathrm{CI}$ & $P$ value & OR & $95 \%$ CI & P value \\
\hline 700 or more $\min$ & 2.56 & $0.81-8.09$ & 0.111 & & & \\
\hline \multicolumn{7}{|l|}{ Interpersonal relationships } \\
\hline $0-4$ points & 1.00 & & & & & \\
\hline $0-5$ points & 1.00 & & & & & \\
\hline Six or more points & 4.28 & $1.34-13.67$ & 0.014 & & & \\
\hline \multicolumn{7}{|c|}{ Evaluation from one's surroundings } \\
\hline $0-2$ points & 1.00 & & & 1.00 & & \\
\hline \multicolumn{7}{|c|}{ Expectation and pressure from others } \\
\hline Six or more points & 1.54 & $0.53-4.51$ & 0.429 & & & \\
\hline \multicolumn{7}{|l|}{ Motivation loss } \\
\hline $0-4$ points & 1.00 & & & & & \\
\hline Five or more points & 3.75 & $1.22-11.54$ & 0.021 & & & \\
\hline \multicolumn{7}{|l|}{ Social support } \\
\hline \multicolumn{7}{|l|}{ Family members } \\
\hline Fifteen or more points & 1.00 & & & 1.00 & & \\
\hline $0-14$ points & 3.65 & $1.20-11.07$ & 0.022 & 3.97 & $1.03-15.25$ & 0.045 \\
\hline \multicolumn{7}{|l|}{ Friends of athletic peers } \\
\hline \multicolumn{7}{|l|}{ Friends of non-athletic peers } \\
\hline \multicolumn{7}{|l|}{ Coaches } \\
\hline $0-14$ points & 1.00 & & & & & \\
\hline Fifteen or more points & 1.48 & $0.43-5.10$ & 0.537 & & & \\
\hline
\end{tabular}

OR: odds ratio; Cl: confidence interval. aFor multivariate analysis, we used the stepwise forward method (likelihood ratio); the factors which had a significant relation with mental health in univariate analysis were only used as independent variables in multivariate analysis.

\section{Acknowledgments}

The authors thank the responsible personnel of each sports organization who kindly arranged to choose the participants of this study.

\section{Financial Disclosure}

This study was supported in part by a grant from Advanced
Research Initiative for Human High Performance (ARIHHP), University of Tsukuba, and a grant from special research funds from Tsukuba University of Technology. The funding source had no role in study design, in the data collection, analysis, interpretation of data, in the writing of the manuscript, or the decision to submit the manuscript for publication.

\section{Conflict of Interest}

The authors declare that they have no conflict of interest. 


\section{Informed Consent}

All subjects provided written informed consent. Before this survey, some explanations were given to each respondent clearly on the front page of each questionnaire and also orally by the persons conducting the survey. The major statements include: the purpose of the study, the ways of protection of privacy, and the other relevant policies of this survey which reveal the fact that we respect the respondent's free will, that the respondent can refuse to answer or stop answering questions at any point while survey is ongoing, and that the submission of a questionnaire is regarded as conscious and valid consent to participate in the survey. For the participants aged below 19 years, additional consent was obtained by sending opt-out documents/forms to their parents or guardians from responsible research coordinator of each sports organization before the official initiation of this survey.

\section{Author Contributions}

YK conducted data collection, analysis, interpretation of data, and wrote the manuscript; TM contributed to the analysis, interpretation of data, and revising the manuscript; MY, TM, and KA contributed to data collection; SJ contributed to revising the manuscript; FT supervised study design, and was involved in analysis, interpretation of data, and revising the manuscript. All authors approved the final version of manuscript.

\section{References}

1. Centers for disease control and prevention: gateway to health communication \& marketing practice. https:// www.cdc.gov/healthcommunication/ToolsTemplates/EntertainmentEd/Tips/Blindness.html. Accessed 5 September 2019.

2. World Health Organization. Global data on visual impairments 2010. https://www.who.int/blindness/ GLOBALDATAFINALforweb.pdf. Accessed 5 September 2019.

3. van der Aa HP, Margrain TH, van Rens GH, Heymans MW, van Nispen RM. Psychosocial interventions to improve mental health in adults with vision impairment: systematic review and meta-analysis. Ophthalmic Physiol Opt. 2016;36(5):584-606.

4. van der Aa HP, Comijs HC, Penninx BW, van Rens GH, van Nispen RM. Major depressive and anxiety disorders in visually impaired older adults. Invest Ophthalmol Vis Sci. 2015;56(2):849-854.

5. Brody BL, Gamst AC, Williams RA, Smith AR, Lau PW, Dolnak D, Rapaport MH, et al. Depression, visual acuity, comorbidity, and disability associated with age-related macular degeneration. Ophthalmology. 2001;108(10):1893-1900.

6. Horowitz A, Reinhardt JP, Kennedy GJ. Major and subthreshold depression among older adults seeking vision rehabilitation services. Am J Geriatr Psychiatry.
2005;13(3):180-187.

7. Mojon-Azzi SM, Sousa-Poza A, Mojon DS. Impact of low vision on well-being in 10 European countries. Ophthalmologica. 2008;222(3):205-212.

8. Chia EM, Wang JJ, Rochtchina E, Smith W, Cumming RR, Mitchell P. Impact of bilateral visual impairment on health-related quality of life: the Blue Mountains Eye Study. Invest Ophthalmol Vis Sci. 2004;45(1):71-76.

9. Kempen GI, Ballemans J, Ranchor AV, van Rens GH, Zijlstra GA. The impact of low vision on activities of daily living, symptoms of depression, feelings of anxiety and social support in community-living older adults seeking vision rehabilitation services. Qual Life Res. 2012;21(8):1405-1411.

10. Fenwick E, Rees G, Pesudovs K, Dirani M, Kawasaki R, Wong TY, Lamoureux E. Social and emotional impact of diabetic retinopathy: a review. Clin Exp Ophthalmol. 2012;40(1):27-38.

11. Augestad LB. Mental health among children and young adults with visual impairments: A systematic review. J Visual Impair Blin. 2017;111:411-425.

12. Koenes SG, Karshmer JF. Depression: a comparison study between blind and sighted adolescents. Issues Ment Health Nurs. 2000;21(3):269-279.

13. Konarska J. Young people with visual impairments in difficult situations. Soc Behav Pers. 2007;35(7):909-918.

14. Garaigordobil M, Bernaras E. Self-concept, self-esteem, personality traits and psychopathological symptoms in adolescents with and without visual impairment. Span J Psychol. 2009;12(1):149-160.

15. Visage L, Loxton H, Ollendick TH, Steel H. Comparing fears in South African children with and without visual impairments. J Visual Impair Blin. 2013;107(3):193-205.

16. Harris J, Lord C. Mental health of children with vision impairment at 11 years of age. Dev Med Child Neurol. 2016;58(7):774-779.

17. Matsunaka K. The effects of social support on daily stress and mental health of visually impaired people. The Japanese Journal of Health Psychology. 2003;16(2):53-59. (In Japanese)

18. Physical Activity Guidelines Advisory Committee. Physical Activity Guidelines Advisory Committee Report. U.S. Department of Health and Human Services; 2008.

19. Sasakawa sports foundation. Sport-life data 2016. 1st Ed. Tokyo: Sasakawa sports foundation, 2017. (In Japanese)

20. Sasakawa sports foundation: Report on sports promotion project for people with disabilities in the region. Sasakawa sports foundation, 2018. (In Japanese)

21. Kondo H, Kohda Y, Kinoshita H, Miyakawa S, Miyamoto T. Survey on physical education of children and students enrolled in special classes for low vision. The Japanese Journal of Para Sports Science. 2018;26:59-65. (In Japanese)

22. Shaprio DR, Moffett A, Lieberman L, Dummer GM. Perceived competence of children with visual impairments. J Visual Impair Blin 2005;99(1):15-25.

23. Lieberman L, McHugh E. Health-related fitness of children who are visually impaired. J Visual Impair Blin. 2001;95(5):272-287. 
24. Stuart M, Lieberman L, Hand K. Beliefs about physical activity among children who are visually impaired and their parents. J Visual Impair Blin. 2006;100(4):223-234.

25. Brunes A, Flanders WD, Augestad LB. The effect of physical activity on mental health among adolescents with and without visual impairment: The Young-HUNT Study, Norway. Br J Vis Impair. 2015;33(3):183-199.

26. Kohda Y, Monma T, Takeda F. The relationship between the mental health of visually impaired students and sports activities in schools. The Bulletin of Health and Sport Sciences, University of Tsukuba. 2015;38:117-121.

27. Furukawa TA, Kawakami N, Saitoh M, Ono Y, Nakane Y, Nakamura Y, Tachimori H, et al. The performance of the Japanese version of the K6 and K10 in the World Mental Health Survey Japan. Int J Methods Psychiatr Res. 2008;17(3):152-158.

28. Kessler RC, Andrews G, Colpe LJ, Hiripi E, Mroczek DK, Normand SL, Walters EE, et al. Short screening scales to monitor population prevalences and trends in non-specific psychological distress. Psychol Med. 2002;32(6):959976.

29. Inoue A, Kawakami N, Tsuchiya M, Sakurai K, Hashimoto H. Association of occupation, employment contract, and company size with mental health in a national representative sample of employees in Japan. J Occup Health. 2010;52(4):227-240.

30. Sakurai K, Kawakami N, Yamaoka K, Ishikawa H, Hashimoto $\mathrm{H}$. The impact of subjective and objective social status on psychological distress among men and women in Japan. Soc Sci Med. 2010;70(11):1832-1839.

31. International Blind Sport Federation. IBSA Classification rules. 2018. http://www.ibsasport.org/documents/files/1821-IBSA-Classification-rules-2018.pdf. Accessed 5 September 2019.

32. Asanuma T, Takeda F, Monma T, Hotoge S. Relationship between mental health and competitive stressor among collegiate athletes - Differences in the level of sense of coherence. Japanese Journal of Health Promotion. 2015;17(1):7-14. (In Japanese)

33. Miura M, Shimada H, Sakano Y. The effects of social support on stress coping in junior high school students. Stress Science Research. 1995;10(1):13-24. (In Japanese)

34. Monma T, Ando A, Asanuma T, Yoshitake Y, Takeda F, Miyazawa T, Ebine N, et al. Sleep disorder risk factors among students athletes. Sleep Med. 2018;44:76-81.

35. Ministry of Health, Labor and Welfare. 2016 Summary of Comprehensive Survey of Living Conditions. (In Japanese) https://www.mhlw.go.jp/toukei/saikin/hw/k- tyosa/k-tyosa16/index.html. Accessed 22 September 2019.

36. Huurre TM, Kommulainen EJ, Aro HM. Relationships with parents and friends, self-esteem and depression among adolescents with visual impairments. Scand J Disabil Res.2001;3(1):21-37.

37. Pinquart M, Pfeiffer JP. Psychological adjustment in adolescents with vision impairment. Int J Disabil Dev Educ. 2012;59(2):145-155.

38. Huurre TM, Aro HM. The psychosocial well-being of Finnish adolescents with visual impairments versus those with chronic conditions and those with no disabilities. J Visual Impair Blin. 2000;94(10):625-637.

39. Emam MM. Problem-solving orientation and attributional style in Egyptian adolescents with visual impairment. Br J Vis Impair. 2013;31(2):150-163.

40. Sullivan P, Blacker M, Murphy J, Cairney J. Levels of psychological distress of Canadian university studentathletes. Can J Higher Edu. 2019;49(1):47-59.

41. Junge A, Feddermann-Demont N. Prevalence of depression and anxiety in top-level male and female football players. BMJ Open Sport Exerc Med. 2016;2(1):e000087.

42. Schaal K, Tafflet M, Nassif H, Thibault V, Pichard C, Alcotte M, Guillet T, et al. Psychological balance in high level athletes: gender-based differences and sport-specific patterns. PLoS One. 2011;6(5):e19007.

43. Dohi M. Feature of female athletes and their issues. J Jp Soc Psychosom Obstet Gynecol. 2017;22(2):141-144. (In Japanese)

44. Nakajima N, Yamada Y. Depression and coping due to stagnation in athletic achievement. Juntendo Medical Journal. 2007;53(1):257-267. (In Japanese)

45. Masubuchi A, Moriya K, Saito F. The relationship of daily and competitive stressor and competitive anxiety in university athletes. Cross-Cultural Business and Cultural Studies. 2016;21(1):171-178. (In Japanese)

46. Pinquart M, Pfeiffer JP. Psychological well-being in visually impaired and unimpaired individuals: A meta-analysis. Br J Vis Impair. 2011;29(1):27-45.

47. Pinquart M, Pfeiffer JP. Change in psychological problems of adolescents with and without visual impairment. Eur Child Adolesc Psychiatry. 2014;23(7):571-578.

48. Halder S, Datta P. Insight into self-concept of the adolescents who are visually impaired in India. Int J Spec Educ. 2012;27(2):86-93.

49. Kef S. The personal networks and social supports of blind and visually impaired adolescents. J Visual Impair Blin. $1997 ; 91(3): 236-244$. 